\title{
HUBUNGAN ANTARA BUDAYA SEKOLAH DAN KOMPETENSI PEDAGOGIK DENGAN KREATIVITAS GURU
}

\author{
Umyati $^{1}$, Sumardi $^{2}$, Eka Suhardi ${ }^{2}$ \\ ${ }^{1}$ Guru SDN Cinyosog I Cileungsi, Bogor, Jawa Barat \\ ${ }^{2}$ Program Pascasarjana Universitas Pakuan, \\ Email: pasca@unpak.ac.id
}

\begin{abstract}
The research aims to know the correlation between school culture, pedagogic competence and teacher creativity severally and jointly. This quantitative research is a survey research that uses correlation approach of two independent variables, namely school culture and pedagogic competence, and teacher creativity as a dependent variable. This research was conducted at Elementary Schools in Bogor District in 2017. The number of research sample is 152 civil servants teachers taken by proportionally random sampling thesis from the population of 245 of State Elementary Schools teachers. There are three main findings; Firstly, there is a positive and highly significant correlation between school culture and the teacher creativity. Secondly, there is a positive and highly significant correlation between pedagogic competence and the teacher creativity. Thirdly, there is a positive and highly significant correlation between school culture and pedagogic competence which is all together with the teacher creativity. The conclusion of the research is that the teacher creativity can be developed by school culture and pedagogic competence severally and jointly..
\end{abstract}

Keywords: school culture, pedagogic competence, teacher creativity

\begin{abstract}
ABSTRAK
Penelitian ini bertujuan untuk mengetahui hubungan antara budaya sekolah dan kompetensi pedagogik guru dengan kreativitas guru secara sendiri-sendiri dan secara bersama-sama. Penelitian kuantitatif ini merupakan penelitian survei dengan pendekatan korelasional yang terdiri atas dua variabel bebas, yaitu budaya sekolah dan kompetensi pedagogik serta kreativitas guru sebagai variabel terikat. Penelitian ini dilaksanakan di SD Negeri di Kecamatan Cileungsi Kabupaten Bogor pada tahun 2017. Jumlah sampel penelitian sebanyak 152 orang guru PNS yang diambil secara proportional random sampling dari populasi sebanyak 245 guru SDN. Temuan dalam penelitian ini yaitu terdapat hubungan positif yang sangat signifikan antara budaya sekolah dengan kreativitas guru, terdapat hubungan positif yang sangat signifikan antara kompetensi pedagogik guru dengan kreativitas guru dan Terdapat hubungan yang sangat signifikan antara budaya sekolah dan kompetensi pedagogik guru secara bersamasama dengan kreativitas guru. Kesimpulan dari penelitian ini yaitu kreativitas guru dapat ditingkatkan dengan budaya sekolah dan kompetensi pedagogik guru secara sendiri-sendiri dan secara bersama-sama.
\end{abstract}

Kata kunci: Budaya sekolah, kompetensi pedagogik, dan kreativitas guru 


\section{PENDAHULUAN}

Sekolah adalah sebuah organisasi pendidikan yang melibatkan beberapa aspek-aspek di dalam pelaksanaannya, aspek-aspek tersebut antara lain kepala sekolah dan dibantu oleh beberapa orang guru juga tata usaha yang bermitra dengan pelaku pendidikan yang berada di masyarakat, diantaranya tokoh pendidikan warga sekitar dan peran anggota komite. Berbagai indikator sekolah yang mendukung kualitas pendidikan diantaranya adalah guru-guru yang profesional. Guru yang berkualifikasi profesional, yaitu guru yang tahu secara mendalam tentang apa yang diajarkannya, cakap dalam mengajarkannya secara efektif dan efisien dan guru tersebut berkepribadian yang mantap.

Melihat uraian di atas banyak guru-guru khususnya di Sekolah Dasar Negeri yang kurang kreatif dalam kinerjanya karena hanya terpaku pada buku guru dan buku siswa, tanpa mencari sumber yang lain untuk pengembangan kognitif. Untuk pengembangan aspek afektif tidak adanya konsistensi penerapan budaya sekolah. Kreativitas guru juga terutama pengoptimalan kompetensi pedagogik guru di sekolah sangat diperlukan untuk meningkatkan wawasan dan kreativitas guru-guru, bahkan terhadap kemajuan sekolah. Dengan demikian, penerapan budaya sekolah harus dapat mengoptimalkan pula kompetensi pedagogik guru, sehingga akan meningkatkan kemampuan dalam menyelesaikan tugas-tugasnya karena selalu berorientasi kepada lahirnya kreativitas guru-guru.

Karena kecakapan dan kreativitas seorang guru yang profesional bukan sekedar hasil pembicaraan atau latihan-latihan yang terkondisi, tetapi perlu pendidikan pra jabatan yang terprogram secara relevan serta berbobot, terselenggara secara efektif dan efisien dan tolak ukur evaluasinya terstandar juga terukur.

\section{Kreativitas Guru}

Kreativitas menurut Sa`nchez Ruiz, et al.,(2011: hh. 461-473), adalah konstelasi faktor seperti ciri-ciri kepribadian, gaya kognitif yang baru. Menurut Ivancevich, Konopaske, dan Matteson (2008: h. 398) bahwa kreativitas adalah sebuah proses dimana seseorang kelompok, atau team yang menghasilkan novel dan ide yang berguna untuk memecahkan masalah atau mengambil sebuah kesempatan. Ogoemeka and Obioma Helen $(2011: h h .124,129)$ menjelaskan bahwa kreativitas adalah suatu proses rekonstruksi ide-ide baru dan mencari berbagai alternatif dalam memecahkan masalah.

Gibson et al.,(2006:hh.119,120) menjelaskan bahwa kreativitas adalah perwujudan ideide (gagasan) yang unggul dalam bentuk peluang atau produk usaha. Kreativitas menurut Colquitt et al., (2011:hh.306,307) adalah penggunaan ide-ide baru dalam bekerja, memecahkan masalah dan melakukan tindakan-tindakan inovatif. Sedangkan McShane (2010:hh.215,218) menjelaskan bahwa "creativity is developing an original product, service, or idea that makes a socially recognized contribution". Artinya bahwa kreativitas adalah mengembangkan produk asli, jasa, atau ide yang membuat kontribusi yang diakui secara sosial. Mir Abdolhasan Askari Rankouh dan Payam Mikbakhsh Saberi Poor (2013:h.27) menjelaskan bahwa kreativitas adalah kemunculan ide-ide baru dalam pikiran seseorang yang diwujudkan sebagai inovasi dalam produk atau jasa.

Berdasarkan teori di atas, dapat disintesiskan bahwa yang dimaksud dengan kreativitas guru dalam penelitian ini adalah tindakan guru yang menghasilkan pemikiran/gagasan baru dalam memecahkan masalah dan melakukan tindakan-tindakan inovatif pada saat kegiatan belajar mengajar.

\section{Budaya Sekolah}

Budaya sangat penting dalam sebuah organisasi (Hidayat, 2018). Menurut Daryanto (2015 : hh. 6-8) budaya sekolah merupakan sekumpulan norma, nilai, dan tradisi yang telah dibangun dalam waktu yang lama oleh semua warga sekolah dan mengarah ke seluruh aktivitas 
personel sekolah, Good berpendapat dalam Adi Kurnia dan Bambang Qomaruzzaman (2012 : hh. 24-25) bahwa budaya sekolah merupakan jaringan kompleks dari berbagai interaksi aktor dalam sekolah yang dimanifestasikan dalam tradisi dan ritual yang dibangun di antara guru, murid, orang tua, administrator untuk menghadapi berbagai tantangan dan mencapai tujuan. Senada dengan Aan Komariah dan Cepi Triatna (2010 : hh. 102 - 108) bahwa budaya sekolah sebagai karakteristik khas sekolah yang dapat diidentifikasi melalui nilai yang dianutnya, sikap yang dimilikinya, kebiasaan - kebiasaan yang ditampilkannya, dan tindakan yang ditunjukan oleh seluruh personel sekolah yang membentuk satu kesatuan khusus dari sistem sekolah.

Pendapat Dadang Suhardan (2010: hh. 121-129) budaya sekolah merupakan variabel yang mempengaruhi bagaimana anggota kelompok bertindak dan berperilaku. Beare dalam Siti Irene Astuti Dwiningrum (2011: hh. 179-187) berpendapat bahwa budaya sekolah pada dasarnya dikonstruksi oleh sekolah untuk mencapai tujuan tertentu dengan menampilkan simbol - simbol tertentu pada masing-masing sekolah.

Berdasarkan deskripsi teoritis di atas dapat disintesiskan bahwa budaya sekolah adalah suatu sistem nilai, kebiasaan dalam suatu sekolah yang dibanagun dari hasil suatu pertemuan antara nilai-nilai yang dianut oleh kepala sekolah dengan nilai-nilai yang dianut oleh guru dan tenaga kependidikkan dalam sekolah tersebut.

\section{Kompetensi pedagogik}

Menurut Mulyasa, Yamin dan Maisah (2010: hh .15,26) kompetensi berasal dari bahasa Inggris yaitu, atau competence yang berarti kemampuan, kecakapan, kompetensi atau keberadaan yang merujuk pada keadaan atau kualitas mampu dan sesuai. Menurut Pendapat Roe dalam Budi (2012, h. 104) kompetensi adalah sebagai kemampuan yang cukup untuk melakukan tugas, tugas atau peran. Moh. Uzer Usman (2010, h.4) menjelaskan kompetensi merupakan kemampuan atau kecakapan. Spencer sebagaimana dikutip Hamzah B. Uno (2008, hh. 129-130) mendefinisikan kompetensi sebagai karakteristik yang mendasari seseorang dan berkaitan dengan efektivitas kinerja individu dalam pekerjaannya.

Deni Koswara dan Halimah (2008, hh. 31-32) berpendapat bahwa kompetensi guru dimaknai sebagai gambaran tentang apa yang seyogyanya dilakukan guru dalam melaksanakan pekerjaannya, baik berupa kegiatan, berperilaku, maupun hasil yang dapat ditunjukkan. Syaiful Sagala (2009, h.32) berpendapat bahwa kompetensi pedagogik adalah kemampuan dalam pengelolaan peserta didik. Janawi (2011, h.65) menjelaskan dimana kompetensi pedagogik adalah kemampuan guru berkenaan dengan penguasaan teoritis dan proses aplikasinya dalam pembelajaran.

Berdasarkan kajian teoritis di atas, maka dapat disintesiskan bahwa kompetensi pedagogik adalah kemampuan pendidik dalam mengelola proses pembelajaran, dan mengembangkan potensi peserta didik secara optimal sehingga menunjukkan tingkat kualitas dari individu tersebut dalam mencapai tujuan pendidikan.

\section{METODE PENELITIAN}

Penelitian ini dilaksanakan di SD Negeri yang berada di wilayah Cileungsi Kabupaten Bogor yang berjumlah 49 Sekolah yang terdiri dari 10 Gugus. Penelitian dilaksanakan mulai Oktober 2017 sampai Februari 2018 dengan rincian kegiatan meliputi tahap persiapan, pelaksanaan dan penyelesaian. Penelitian ini menggunakan jenis penelitian deskriptif kuantitatif, yaitu metode survei dengan teknik korelasional.

Populasi pada penelitian ini bersifat homogen yaitu seluruh guru SDN di Wilayah Cileungsi Kab. Bogor, dengan jumlah 245 orang yang berstatus PNS dari 49 SDN, dengan sampel 152 responden. Uji coba instrumen dilakukan melalui teknik korelasi Product Moment Pearson. Uji Reliabilitas instrumen penelitian menggunakan perhitungan Alpha Cronbach. 
Sedangkan analisis data menggunakan statistik inferensial dengan menggunakan uji analisis varians regresi.

\section{HASIL PENELITIAN}

\section{Pengujian Persyaratan Analisis}

\section{Uji Normalitas}

a. Uji normalitas pada Galat Baku Taksiran Variabel Kreativitas Guru (Y) atas variabel Budaya Sekolah $\left(\mathbf{X}_{1}\right)$

Hasil pengolahan data uji normalitas galat baku taksiran $\left(\mathrm{Y}-\hat{Y}_{1}\right)$ variabel kreativitas guru $(\mathrm{Y})$ atas budaya sekolah $\left(\mathrm{X}_{1}\right)$ diperoleh skor $\mathrm{L}_{\mathrm{o}}$ maksimum 0,0698 , dengan $\mathrm{L}_{\mathrm{t}}$ sebesar 0,0723. Persyaratan normal adalah $\mathrm{L}_{\mathrm{o}}<\mathrm{L}_{t}$ dengan demikian galat baku taksiran $\left(\mathrm{Y}-\hat{\mathrm{Y}}_{1}\right)$ variabel kreativitas guru $(\mathrm{Y})$ atas variabel budaya sekolah $\left(\mathrm{X}_{1}\right)$ berasal dari populasi yang berdistribusi normal.

\section{b. Uji normalitas Galat Baku Taksiran Variabel Kreativitas Guru (Y) atas variabel Kompetensi Pedagogik $\left(\mathbf{X}_{2}\right)$}

Hasil perhitungan normalitas galat baku taksiran $\left(\mathrm{Y}-\hat{\mathrm{Y}}_{2}\right)$ variabel Kreativitas guru $(\mathrm{Y})$ atas kompetensi pedagogik $\left(\mathrm{X}_{2}\right)$ diperoleh skor $\mathrm{L}_{\mathrm{o}}$ maksimum 0,0673 , sementara $\mathrm{L}_{\mathrm{t}}$ sebesar 0,0723. Persyaratan normal adalah $\mathrm{L}_{\mathrm{o}}<\mathrm{L}_{\mathrm{t}}$ dengan demikian galat baku taksiran $\left(\mathrm{Y}-\hat{\mathrm{Y}}_{2}\right)$ variabel Kreativitas guru $(\mathrm{Y})$ atas variabel kompetensi pedagogik $\left(\mathrm{X}_{1}\right)$ berasal dari populasi yang berdistribusi normal.

\section{Uji Homogenitas}

a. Uji Homogenitas Budaya Sekolah $\left(\mathrm{X}_{1}\right)$ dengan Kreativitas Guru (Y)

Homogenitas varians kelompok data variabel kreativitas guru (Y) atas variabel budaya sekolah $\left(\mathrm{X}_{1}\right)$ di uji dengan menggunakan aplikasi data analysis pada Mc.exel F-Test TwoSample for Variances, berdasarkan hasil perhitungan diperoleh skor $\chi^{2}$ hitung sebesar 0,379

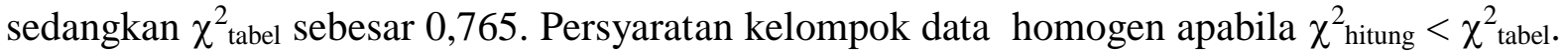
Kesimpulannya variansi skor data variabel kreativitas guru $(\mathrm{Y})$ atas variabel budaya sekolah $\left(\mathrm{X}_{1}\right)$ dikelompokan adalah berasal dari populasi yang homogen.

\section{b. Uji Homogenitas Kompetensi Pedagogik ( $\left.\mathbf{X}_{2}\right)$ dengan Kreativitas Guru (Y)}

Homogenitas varians kelompok data variabel Kreativitas guru (Y) atas variabel Kompetensi pedagogik $\left(\mathrm{X}_{2}\right)$ di uji dengan menggunakan aplikasi data analysis pada Mc.exel F-Test Two-Sample for Variances. Berdasarkan hasil perhitungan diperoleh skor $\chi^{2}$ hitung sebesar 0,039 sedangkan $\chi_{\text {tabel }}^{2}$ sebesar 0,765. Persyaratan kelompok data homogen apabila $\chi^{2}$ hitung $<\chi_{\text {tabel. }}^{2}$

\section{Pengujian Hipotesis}

\section{A. Uji Regresi dan Korelasi}

1. Hubungan antara Budaya sekolah $\left(\mathrm{X}_{1}\right)$ dengan Kreativitas Guru (Y)

Pengujian linieritas persamaan regresi $\hat{\mathrm{Y}}=23,37+0,79 \mathrm{X} 1$ dilakukan dengan menggunakan uji F. Persyaratan persamaan regresi dikatakan linier apabila $F_{\text {hitung }}<F_{\text {tabel }}$. Berdasarkan hasil perhitungan seperti tertera pada tabel 15, diperoleh skor $F_{\text {hitung }}$ sebesar 0,47 sedangkan skor $F_{\text {tabel }}$ sebesar 1,75 dengan demikian maka persamaan regresi $\hat{Y}=23,37+$ 0,79X1 adalah bersifat linier.

Berdasarkan hasil analisis regresi terhadap variabel budaya sekolah $\left(\mathrm{X}_{1}\right)$ dengan variabel kreativitas guru (Y), maka dapat disimpulkan bahwa persamaan regresi $\hat{\mathrm{Y}}=23,37+0,79 \mathrm{X} 1$ adalah signifikan dan linier. Berdasarkan hasil pengujian terhadap hipotesis pertama, dapat 
disimpulkan bahwa $\mathrm{H}_{\mathrm{o}}$ diterima, artinya $\mathrm{H}_{1}$ (hipotesis ditolak) menyatakan terdapat hubungan positif antara variabel budaya sekolah $\left(\mathrm{X}_{1}\right)$ dengan variabel kreativitas guru (Y) adalah nyata.

\section{Hubungan Kompetensi Pedagogik $\left(\mathbf{X}_{2}\right)$ dengan Kreativitas Guru ( $(Y)$}

Pengujian linieritas persamaan regresi $\hat{\mathrm{Y}}=76,99+1,72 \mathrm{X} 2$ dilakukan dengan menggunakan uji $\mathrm{F}$. Persyaratan persamaan regresi dikatakan linier apabila $F_{\text {hitung }}<\mathrm{F}_{\text {tabel. }}$. Berdasarkan hasil perhitungan seperti tertera pada tabel di atas, diperoleh skor $F_{\text {hitung }}$ sebesar 0,53 lebih kecil dari skor $F_{\text {tabel }(\alpha=0,05)}$ sebesar 1,79 dengan demikian maka persamaan regresi $\hat{\mathrm{Y}}=76,99+1,72 \mathrm{X} 2$ adalah bersifat linier. Hubungan antara variabel kompetensi pedagogik $\left(\mathrm{X}_{2}\right)$ dengan variabel kreativitas guru $(\mathrm{Y})$ ditunjukkan oleh skor koefisien determinasi $\left(\mathrm{r}_{\mathrm{y} 2}^{2}\right)$. Skor $\mathrm{r}_{\mathrm{y} 2}^{2}$ menunjukkan adanya kontribusi variabel Kompetensi pedagogik $\left(\mathrm{X}_{2}\right)$ dapat mempengaruhi kreativitas guru (Y).

Mencermati hasil perhitungan seperti pada tabel di atas, diperoleh $t_{\text {hitung }}$ sebesar 4,03 sedangkan $t_{\text {tabel }}(\alpha=0,05)$ sebesar 1,66 ( $\left.\left.\mathrm{dk}=152-2=150\right), \alpha=0.05\right)$ (Sambas Ali Muhidin, Maman Abdurahman, 2007: h. 266). Hal ini berarti bahwa koefisien korelasi antara variabel kompetensi pedagogik $\left(\mathrm{X}_{2}\right)$ dengan variabel kreativitas guru $(\mathrm{Y})$ adalah sangat signifikan.

\section{Hubungan antara Budaya Sekolah $\left(X_{1}\right)$ dan Kompetensi Pedagogik $\left(X_{2}\right)$ secara bersama-sama dengan Kreativitas Guru (Y)}

\section{a. Uji Regresi Ganda}

Hubungan fungsional antara budaya sekolah $\left(\mathrm{X}_{1}\right)$ dan kompetensi pedagogik $\left(\mathrm{X}_{2}\right)$ dengan kreativitas guru $(\mathrm{Y})$ dapat disajikan dalam bentuk persamaan regresi sebagai berikut $\hat{\mathrm{Y}}=9,06$ $+0,68 X 1+1,07 X 2$. Melihat hasil perhitungan uji signifikansi regresi diperoleh $F_{\text {hitung }}$ sebesar 28,06 sedangkan $\mathrm{F}_{\text {tabel }(\alpha=0,05)}$ sebesar 3,91, hal ini menunjukkan bahwa hubungan antara budaya sekolah $\left(\mathrm{X}_{1}\right)$ dan kompetensi pedagogik $\left(\mathrm{X}_{2}\right)$ secara bersama-sama dengan kreativitas guru (Y) adalah nyata.

\section{b. Uji Korelasi Ganda}

Koefisien korelasi ganda berdasarkan hasil perhitungan seperti tampak pada tabel di atas, diperoleh $F_{\text {hitung }}$ sebesar 28,06, $F_{\text {tabel }}(\alpha=0,05)$ sebesar 3,89 dan $F_{\text {tabel }(\alpha=0,01)}$ sebesar 6,78 (Sambas Ali Muhidin, Maman Abdurahman, 2007: h. 269). Hal ini berarti bahwa koefisien korelasi antara budaya sekolah $\left(\mathrm{X}_{1}\right)$ dan variabel kompetensi pedagogik $\left(\mathrm{X}_{2}\right)$ secara bersama-sama dengan kreativitas guru (Y) adalah nyata.

Skor koefisien determinasi antara budaya sekolah $\left(\mathrm{X}_{1}\right)$ dan variabel kompetensi pedagogik $\left(\mathrm{X}_{2}\right)$ secara bersama-sama dengan kreativitas guru $(\mathrm{Y})$ adalah $\left(\mathrm{r}_{\mathrm{y} .12}^{2}\right)$ sebesar 0,2736. Skor koefisien determinasi tersebut menunjukkan bahwa 27,36 \% kreativitas guru (Y) dapat dijelaskan oleh variabel budaya sekolah $\left(\mathrm{X}_{1}\right)$ dan variabel kompetensi pedagogik $\left(\mathrm{X}_{2}\right)$ secara bersama-sama.

\section{Uji Korelasi Parsial}

Untuk menguji signifikansi koefisien korelasi parsial variabel kompetensi pedagogik sebagai kontrol dengan skor $t_{\text {hitung }}$ sebesar 7,24 sedangkan skor $t_{\text {tabel }}$ sebesar 1,66. Skor $t_{\text {hitung }}$ yang lebih besar skor $t$ tabel menunjukkan bahwa bahwa hubungan antara budaya sekolah dengan kreativitas guru, dimana skor kompetensi pedagogik dikontrol adalah signifikan. Perhitungan korelasi parsial antara kompetensi pedagogik dengan kreativitas guru, jika budaya sekolah dikendalikan menghasilkan skor $\mathrm{r}_{\mathrm{y} 2.1}=0,3703$, dengan skor $\mathrm{t}$ hitung $=4,38$ (Lampiran 9: hh. 212-214), sedangkan skor $\mathrm{t}_{\text {tabel }}=1$,66. Perhitungan skor $\mathrm{t}_{\text {hitung }}$ lebih besar dari $\mathrm{t}$ tabel menunjukkan bahwa hubungan antara kompetensi pedagogik dengan kreativitas guru, dimana skor budaya sekolah dikontrol signifikan. 


\section{PEMBAHASAN}

\section{Hubungan antara Budaya Sekolah dengan Kreativitas Guru}

Berdasarkan hasil perhitungan koefisien korelasi antara budaya sekolah $\left(\mathrm{X}_{1}\right)$ dengan Kreativitas guru (Y) dapat disimpulkan bahwa terdapat hubungan positif yang sangat signifikan antara budaya sekolah dengan Kreativitas guru, karena diperoleh besarnya skor koefisien korelasi $\mathrm{r}_{\mathrm{y} 1}=0,4831$. Kontribusi budaya sekolah $\left(\mathrm{X}_{1}\right)$ dalam menerangkan Kreativitas guru melalui skor koefisien determinasi $r_{\mathrm{y} 1}{ }^{2}=0,2334(23,34 \%)$ karena diperoleh skor $t_{\text {hitung }}=5,66>t_{\text {tabel }}=1,66$ pada taraf signifikan 0,05 .

Hasil penelitian ini sejalan hasil penelitain Jakiyah, Sumardi, Hidayat (2018) bahwa budaya dalam organisasi memengaruhi berbagai aktivitas sumdar daya manusia dalam organisasi. Oleh karena itu untuk meningkatkan kreativitas guru maka harus ditingkatkan budaya sekolah antara lain meliputi budaya yang berkaitan dengan sikap disiplin, jujur, menjalin hubungan yang sederhana antar orang dan bagian, dan berwawasan luas. inisiatif, kebersamaan, tanggung jawab, rasa memiliki, dan komitmen terhadap lembaga. Selain itu pula guru harus menjalin kerja sama, saling pengertian, semangat persatuan, taat atas memotivasi, dan semangat membimbing peserta didik dalam mencapai tujuan sekolah.

\section{Hubungan antara Kompetensi Pedagogik dengan Kreativitas Guru}

Berdasarkan hasil perhitungan koefisien korelasi antara kompetensi pedagogik $\left(\mathrm{X}_{2}\right)$ dengan kreativitas guru (Y) dapat disimpulkan bahwa terdapat hubungan positif yang sangat signifikan antara kompetensi pedagogik dengan kreativitas guru, karena diperoleh besarnya skor koefisien korelasi $r_{\mathrm{y} 2}=0,3395$. Hal ini terlihat dari skor $F_{\text {hitung }} 11,68>F_{\text {tabel }} 3,90$ pada taraf signifikan 0,05. Persamaan regresi tersebut dapat digunakan untuk memprediksi skor kreativitas guru (Y) melalui skor kompetensi pedagogik. Kontribusi kompetensi pedagogik $\left(\mathrm{X}_{2}\right)$ dalam menerangkan Kreativitas guru $(\mathrm{Y})$ melalui skor koefisien determinasi $\mathrm{r}_{\mathrm{y} 2}{ }^{2}=0,1152$ $(11,52 \%)$ karena diperoleh skor $t_{\text {hitung }}=5,66>\mathrm{t}_{\text {tabel }}=1,66$ pada taraf signifikan 0,05.

Dengan demikian dapat diartikan bahwa terdapat hubungan positif yang signifikan, antara kompetensi pedagogik dengan kreativitas guru. Semakin tinggi tingkat kompetensi pedagogik, diprediksi akan semakin tinggi pula taraf kreativitas guru. Temuan ini sejalan dengan Manurung et all (2018) bahwa budaya akademik memengaruhi kreativitas para pengajar dalam sebuah institusi pendidikan. Oleh karena itu kompetensi pedagogic perlu terus dikembangkan dalam meningkatkan kreativitas guru.

\section{Hubungan positif antara budaya sekolah dan kompetensi pedagogik secara bersama-sama dengan kreativitas guru}

Berdasarkan pada hasil penelitian dapat disimpulkan terdapat hubungan positif yang sangat signifikan antara budaya sekolah $\left(\mathrm{X}_{1}\right)$ dan kompetensi pedagogik $\left(\mathrm{X}_{2}\right)$ secara bersamasama dengan kreativitas guru (Y). Hasil uji signifikan korelasi ganda terhadap kekuatan hubungan antara budaya sekolah $\left(\mathrm{X}_{1}\right)$ dan kompetensi pedagogik $\left(\mathrm{X}_{2}\right)$ secara bersama-sama dengan kreativitas guru (Y) diperoleh $\mathrm{r}_{\mathrm{y} 12}=0,5231$. Hasil uji signifikansi korelasi ganda diperoleh $F_{\text {hitung }}=28,06$ lebih besar dari $F_{\text {tabel }}=3,90$ pada taraf signifikan 0,05, maka hipotesis yang diterima adalah $\mathrm{H}_{1}$. Demikian, dapat disimpulkan terdapat hubungan positif yang sangat signifikan antara budaya sekolah dan kompetensi pedagogik secara bersama-sama dengan kreativitas guru.

Berdasarkan pembahasan di atas, maka kreativitas guru dapat ditingkatkan melalui perbaikan budaya organisasi sekolah dan perbaikan komptensi pedagogic para guru baik secara bersama-sama atau sendiri-sendiri. 


\section{SIMPULAN}

Berdasarkan analisis terhadap data hasil penelitian dapat disimpulkan terdapat hubungan positif sangat signifikan antara budaya sekolah dengan kreativitas guru, antara kompetensi pedagogik dengan kreativitas guru, antara budaya sekolah dan kompetensi pedagogik secara bersama-sama dengan kreativitas guru. Temuan dari penelitian ini merekomendasikan untuk meningkatkan kreativitas guru dapat dilakukan dengan meningkatkan budaya sekolah dan pengembangan pada kreativitas guru.

\section{DAFTAR PUSTAKA}

Aan Komariah dan Cepi Triatna, Visionary Leadership Menuju Sekolah Efektif, Jakarta: Bumi Aksara 2010.

Abdul Hadis dan Nurhayati B, Manajemen Mutu Pendidikan, Bandung: Alfa beta, 2010.

Anderson, Lorin W. Dan David R,Krathwohl. Kerangka Landasan untuk Pembelajaran, Pengajaran, dan Asesmen. Yogyakarta: Pustaka pelajar. 2015.

Budi Suhardiman. Studi Pengembangan Kepala Sekolah, Jakarta: PT. Rineka Cipta, 2012.

Colquitt, J.A., Lepine J.A., \& Wesson, M.J., Organizational Behavior. New York: McGrawHill, 2011.

Dadang Suhardan, Supervisi Profesional (layanan meningkatkan mutu pembelajaran di era otonomi daerah), Bandung: Alfabeta 2010.

DeGraff, Jeff., \& Lawrence, Katherine A., Creativity at Work, Uniteed States Of America: Jhon Wiley \& Sons, 2002

Deni Koswara dan Halimah, Seluk Beluk Profesi Guru, Bandung: PT Bumi Mekar, 2008.

E. Mulyasa, Standar Kompetensi dan Sertifikasi Guru, Bandung: PT. Remaja Rosdakarya, 2007.

Fred Luthans, Organizational Behavior, New York : McGraw-Hill Irwin, 2011.

Gibson, J.L., Ivancevich, J.M., Donnely, J.H., \& R. Konopaske. Organizations: Behavior, Structure \& Process. New York: McGraw-Hill, 2006.

Greenberg, Jerald., and Baron, Robert A., Behavior in Organizations: Organizational Culture, Creativity and innovation, New jersey: Pearson, 2011.

Hamzah B.Uno. Orientasi Baru dalam Psikologi Pembelajaran, Jakarta: PT Bumi Aksara, 2008.

Hidayat Rais, Henny Suharyati, Yuyun Elizabeth Patras, Sutji Harjanto, Haposan Andi. 2018. Optimalisasi Budaya Mutu Sekolah Untuk Meningkatkan Komitmen Guru. Jurnal Manajemen Pendidikan, Vol. 6 No. 1 
Ivancevich, Konopaske, Matteson, Organization Bahavior and Management, New York: Mc Graw Hill-International Edition, 2008.

Kreitner, Robert., \& Kinicki, Angelo., Organizational Behavior, (New York; McGraw Hill, 2008

Janawi, Kompetensi Guru Citra Guru Profesional, Bandung: Alfabeta, 2011.

Jakiyah Atiyatu, Sumardi Sumardi, Rais Hidayat. Peningkatan Produktivitas Kerja Guru Melalui Pengembangan Kepemimpinan Transformasional Dan Budaya Organisasi. Jurnal Manajemen Pendidikan Vol.6, No.2, Juli 2018, hh. 2614-3313

Manurung Santa, Rais Hidayat, Yuyun Elizabeth Patras, Rhini Fatmasari. Peningkatan Efektivitas Kerja melalui Perbaikan Pelatihan, Penjaminan Mutu, Kompetensi Akademik dan Efikasi Diri dalam Organisasi Pendidikan. Manageria: Jurnal Manajemen Pendidikan Islam Volume 3, Nomor 1, Mei 2018/1439

M. Sackhan Muchith, Pembelajaran Kontekstual, Semarang: RaSail Media Group, 2007.

McShane and Von Glinow, Organizational Behavior, New York: McGraw Hill, 2010.

Muhamin, Manajemen Pendidikan Dalam Penyusunan Rencana Pengembangan Sekolah Madrasah, Jakarta: Kencana 2010.

Mulyasa, Standar Kompetensi dan Sertifikasi Guru, Bandung: PT Remaja Rosdakarya, 2009.

Mohammad Ali dan Mohammad Asrori, Psikologi Remaja: Perkembangan Peserta Didik, Bandung: Bumi Aksara, 2011.

Oemar Hamalik, Perencanaan Pengajaran Berdasarkan Pendekatan Sistem, Jakarta: Bumi Aksara, 2010.

Ogoemeka and Obioma Helen, Emotional Intellegence and Creativity in Teacher Education, International Journal of Psychology and Counselling, 2011.

Rankouh, Mir Abdolhasan Askari., and Poor, Payam Mikbakhsh Saberi., Ekamine the Relationship beteen Organization Culture and Creativity of Lecturers, Universal Journal Of management and Social Science, 2013.

Slemanto, Belajar Dan Faktor-Faktor Yang Mempengaruhinya, Jakarta: Rineka Cipta, 2010.

Stephen Robbins, Organizational Behavior, Concepts, Controversies, Applications, New Jersey: Prentice-Hall International,Inc. A.Simon \& Schuster, 2008.

Sa`nchez Ruiz, M.J., \& Torrano, D. Hernandez., Gonzales, J.C Perez, M. Batey, and Petrides, K.V., Motivation \& Inovation: The relationship between trait Emotional Intellegence and Creativity Across Subject Domain, Springer: 2011. 
Syaiful Sagala, Kemampuan Profesional Guru dan tenaga kependidikan, Bandung: Alfabeta, 2009.

Siti Irene Astuti Dwiningrum, Desentralisasi dan Partisipasi Masyarakat Dalam Pendidikan, Yogyakarta: Pustaka Pelajar, 2011.

Syamsul Ma'arif, Guru Profesional Harapan dan Kenyataan, Semarang:Walisongo Press, 2011.

Wayney K.Hoy dan Cecil G. Miskel, Adminitrasi Pendidikan Teori, Riset, dan Praktik Yogyakarta; Pustaka Belajar, 2014.

Yeni Rachmawati dan Euis Kurniati, Strategi Pemgembangan Kreativitas pada Anak, Jakarta: Kencana, 2010. 